\title{
Effects of Endogenous Hormones and Sugars on Fruit Size Driven by Cell Division between Korla Fragrant Pear and Its Bud Mutation
}

\author{
Jia Tian and Yue Wen \\ Research Center for Xinjiang Characteristic Fruit Tree, College of Forestry \\ \& Horticulture, Xinjiang Agricultural University, 830052, Urumqi, China
}

\author{
Feng Zhang \\ Research Center for Xinjiang Korla Fragrant Pear, 841000, Korla, China
}

\begin{abstract}
Jingyi Sai, Yan Zhang, and Wensheng Li
Research Center for Xinjiang Characteristic Fruit Tree, College of Forestry \& Horticulture, Xinjiang Agricultural University, 830052, Urumqi, China
\end{abstract}

Additional index words. carbohydrate, cell volume, cell number, fruit development, pear, phytohormones

\begin{abstract}
Large-fruit bud mutations are important factors in fruit tree breeding. However, little is known about the differences between varieties and bud mutations. The ploidy identification of Korla fragrant pear (Pyrus sinkiangensis Yu) and its large bud mutation Zaomeixiang pear showed that the large-fruit characteristic was not caused by chromosome doubling. By counting mesocarp cells at different stages, we found that the number of cells increased continuously after pollination, and the difference was the greatest at 28 days after full bloom (DAFB), and was about $9.4 \times 10^{6}$. After 28 days, the difference in cell volume became bigger and bigger, so both the cell volume and cell number caused the difference in fruit size between Korla fragrant pear and Zaomeixiang pear. To obtain more insights into the differences in fruit size driven by cell division, we analyzed the endogenous hormones [indole ascetic acid (IAA), zeatin riboside (ZR), gibberellic acid (GA), and abscisic acid (ABA)], and the main sugars (glucose, fructose, sucrose, and sorbitol). The ZR content of Zaomeixiang pear was always greater than that of Korla fragrant pear at all stages. The ABA content was the opposite except for at 7 DAFB during cell division; the greatest difference was $30.87 \mathrm{ng} / \mathrm{g}$, which appeared at $28 \mathrm{DAFB}$. ABA and ZR correlated negatively with cell number. After 7 DAFB, the ratio of IAA/ABA, ZR/ABA, and GA/ABA in Zaomeixiang pear was always greater than that for Korla fragrant pear at 28 DAFB. The difference in glucose content at 21 DAFB was the greatest, at $4.80 \mathrm{ng} / \mathrm{g}$. Large amounts of sorbitol accumulated during whole-cell division. Glucose and sorbitol correlated positively with cell numbers. In summary, the data suggest that the different contents of glucose, sorbitol, $Z R$, and $A B A$, and the ratio of endogenous hormones might be related to cell division in Korla fragrant pear and Zaomeixiang pear. The result provides a theoretical basis for the large-size fruit's high-quality production and genetic breeding of Korla fragrant pear and its bud mutation.
\end{abstract}

Fruit size is an important component of appearance quality and one of the important factors determining the economic value of fruit trees. Fruit size is determined by both cell size and cell number (Breuninger and Lenhard

Received for publication 11 Feb. 2021. Accepted for publication 5 May 2021.

Published online 18 June 2021.

J.T. and Y.W. contributed equally to this work. This research was funded by the Natural Science Foundation of China (31760561) and the Xinjiang Uygur Autonomous Region Horticulture Key Discipline Fund (2016-10758-3).

W.L. is the corresponding author. E-mail: wenshengli1968@163.com.

This is an open access article distributed under the CC BY-NC-ND license (https://creativecommons. org/licenses/by-nc-nd/4.0/).
2010; Gonzalez et al., 2012; Lim et al., 2018). During the early stage of fruit growth and development, fruit size is based on an increase in the number of cells. During the later stage, cell expansion is dominant. In most fruit trees, such as apple, peach, avocado, pear, and plum, the number of cells has a greater influence on the final size of the fruit than cell size (Cerri et al., 2019; Dahan et al., 2010; Filipe et al., 2019; Nagashima et al., 2019; Tian et al., 2016; Zhang et al., 2019).

Cell division is affected by endogenous hormones and sugars. Endogenous hormones are important signaling substances synthesized in plants, and are involved in the regulation of cell division and expansion (Liu et al., 2020). As the main metabolic material, sugars provide raw materials for plant growth and respond to the regulatory effects of endogenous hormones (Simona et al., 2020). During fruit development in raspberry, before the onset of ripening, fruit size, weight, and IAA levels increased (Maricarmen et al., 2019). Research of citrus showed that the difference in fruit size was related closely to the increase in IAA levels, and greater ABA levels may inhibit fruit growth and cell expansion (Liu et al., 2015). Fruit growth was promoted, and sucrose accumulated preferentially in the Japanese pear 'Kosui', with more large cells induced by GA treatment (Kano, 2003). A study of Dangshansu pear showed that GA, IAA, and ZR might be related to cell division and expansion of pear fruit during the early stage, whereas ABA mainly promoted the accumulation of assimilates (Liu et al., 2006). Different proportions of endogenous hormone contents also affect fruit size. Research has shown that greater ratios of IAA/ABA, ZR/ $\mathrm{ABA}$, and GA/ABA correlated positively with fruit size (Liao et al., 2018; Nicky and Keith 2001). In some tomato varieties, there is believed to be a trade-off between fruit sugar content and yield (Kanayama 2017). The fruit development and sugar accumulation of large and small fruit of Hosui pear and Yali pear showed that the sugar accumulation ability of small fruit was less. The difference in sugar accumulation between large fruit and small fruit in Hosui pear was caused primarily by sucrose, whereas the sucrose, fructose, glucose, and sorbitol contents of large fruit in Yali pear were greater than those of small fruit $(\mathrm{Wu}$, 2011). Bud mutation is a change in the genetic material occurring in the cells of the bud meristem and is very important for new variety selection (Hu et al., 2012; Zhao et al., 2019). In pear, large-fruit bud varieties have been selected from many varieties, such as Nanguo pear and Cuiguan pear. Understanding the mechanism of large-fruit bud mutations will help us to carry out bud selection work more thoroughly and efficiently (Shu et al., 2017).

Korla fragrant pear (Pyrus sinkiangensis $\mathrm{Yu}$ ) is a famous fruit tree in Xinjiang and has a cultivation history of more than 1400 years. The fruit of Korla fragrant pear has a mild, fragrant taste, and the sarcocarp is crisp, succulent, sweet, and refreshing; rich in vitamin $\mathrm{C}$; and has a long storage life ( $\mathrm{Li}$ et al., 2007). Korla fragrant pear production has already become one of the pillar industries of local agriculture. However, the fruit size of Korla fragrant pear is small, with the average fruit weighing less than $100 \mathrm{~g}$, which affects the economic value and development of the Korla fragrant pear industry. Zaomeixiang is an excellent new variety selected from bud mutations of Korla fragrant pear. It not only maintains the intrinsic quality of Korla fragrant pear, but also has stable genetic characteristics and excellent comprehensive traits. In particular, the fruit size is much larger than that of Korla fragrant pear, with an average fruit weight of $200 \mathrm{~g}$, which is highly beneficial for commercial production and more competitive in the market. However, Zaomeixiang pear has poor cold resistance and is vulnerable to freezing damage. A large area of Zaomeixiang pear planted in Korla pear 
production areas died as a result of exposure to low temperatures in 2011. Because Zaomeixiang pear has a similar genetic background to Korla fragrant pear, it is an ideal mutant material to study the fruit size variation mechanism of Korla fragrant pear. To determine the difference in fruit size between Korla fragrant pear and Zaomeixiang pear, cell size and cell numbers were measured during the entire fruit development period, and the major endogenous hormones and sugars were determined during cell division to provide a theoretical basis for the high-quality production and genetic breeding of Korla fragrant pear and its bud mutation.

\section{Materials and Methods}

Plant materials. A field experiment was conducted at the Shayidong horticultural field, Korla, Xinjiang, China (lat. $41^{\circ} 36^{\prime} 54^{\prime \prime}$, long. $\left.86^{\circ} 00^{\prime} 40^{\prime \prime} \mathrm{E}\right)$ under natural conditions. The experimental site was the main growing area for Korla fragrant pear and Zaomeixiang pear. Trees were grown in north to south rows spaced $4 \times 5 \mathrm{~m}$.

Three 25-year-old Korla fragrant pear and three Zaomeixiang pear plants with strong growth vigor were used in this experiment. The fruit of Korla fragrant pear and Zaomeixiang pear was collected separately at 7, 14, 21, $28,35,42,56,70,84,98,112,126,140$, and $154 \mathrm{~d}$ DAFB in the morning. From pollination to $42 \mathrm{DAFB}$, cell division was robust and the number of cells increased rapidly. However, after 56 DAFB, the number of cells stopped growing and the cell number became stable. In general, we focused on the relationship between cell division and fruit size. Young leaves were also collected separately for ploidy determination. Fruit of each cultivar were fixed in formalin-aceto-alcohol (FAA) solution to measure fruit cell size and number. In addition, fruit were frozen in liquid nitrogen and then preserved at $-80^{\circ} \mathrm{C}$ for the determination of sugars and endogenous hormones.

Ploidy determination. Ten leaves of each cultivar in each stage were collected randomly. Referring to the conventional genome size determination method, the ploidy of Zaomeixiang pear was determined by the DNA content of the young leaves using flow cytometry (LSRFortessa; Becton, Dickinson and Company, Franklin Lakes, NJ). The system light source was a 488-nm argon particle laser, and Korla fragrant pear was used as a control.

Measurement of fruit volume and fruit weight. Thirty fruit of each cultivar in every stage were collected randomly, and then the mass, diameter, and length were determined using a vernier caliper. The average fruit volume $(V)$ was calculated using the formula $V=$ $4 / 3 \pi d^{3}$ (Zhang and Ma 1995), where $d$ is half the average value of the fruit width and length.

Measurement of fruit cell size and number. Ten fruit of each cultivar in each stage were collected for the fixation of paraffin sections. Cell number along the equatorial region of the mesocarp can be regarded as an indicator of fruit fresh weight or fruit size (Zhang et al., 2006). The mesocarp samples were fixed in FAA solution, dehydrated in a graded ethanol series, and embedded in wax. Fruit sections (10-12 $\mu \mathrm{m}$ thick) were prepared using a rotary microtome (ERM 3100; Hestion, Jiangsu, China), dewaxed, and stained with safranin and fast green. All the samples were examined and photographed on a $4 \times / 0.10$ plane using a Nikon Eclipse 80i microscope (Nikon, Tokyo, Japan). To determine the average cell volume, the width and length of cells/ $1-\mathrm{mm}^{2}$ unit area were measured from microscopic images, corresponding to different stages of fruit development. The cell width and length were attained by crosswise and lengthwise analyses, respectively, of six randomly selected areas of fruit mesocarp images, excluding the epidermis, hypodermis, and/or vascular bundles. Treating the cell as a sphere, cell volume was calculated using the formula mentioned earlier $\left(V=4 / 3 \pi d^{3}\right.$, where $d$ denotes half the average value of the cell width and length). The average cell number was the ratio of the fruit volume and cell volume, repeated three times. Cell division was determined according to the period during which the cell number increased.

Determination of sugars. Ten fruit of each cultivar in each stage were used to determinate sugars and endogenous hormones. The frozen mesocarp materials $(1.0 \mathrm{~g})$ were homogenized in $5 \mathrm{~mL}$ deionized distilled water using a mortar and pestle. The supernatant was collected after centrifugation at $10,000 g_{\mathrm{n}}\left(4^{\circ} \mathrm{C}\right)$ for $15 \mathrm{~min}$. The supernatant was collected through a $0.22-\mu \mathrm{m}$ Millipore membrane (Millipore, Burlington, MA). Glucose, fructose, sucrose, and sorbitol contents were measured by highperformance liquid chromatography using an Agilent 1260 infinity autosampler (Agilent Technologies, Santa Clara, CA) equipped with a refractive index detector and an Agilent Hi-Plex Ca column $(8.0 \mu \mathrm{m}, 7.7 \times 300 \mathrm{~mm})$. The analytical conditions used were as follows: flow, 0.50 $\mathrm{mL} \cdot \mathrm{min}^{-1}$; column temperature, $80^{\circ} \mathrm{C}$; and injection volume, $20 \mu \mathrm{L}$. Peak heights were measured using a dual-channel computer integrator. Individual sugars were identified by comparing retention times with authentic standards, and their concentrations were determined using the external standard method (Zaky et al., 2017). Each sugar was assayed in triplicate.

Determination of endogenous hormones. The frozen mesocarp materials $(0.5-1.0 \mathrm{~g})$ were homogenized in $2 \mathrm{~mL}$ cold extraction solution $(80 \%$ methanol with $1 \%$ butylated hydroxytoluene antioxidant) containing $0.1 \mathrm{~g}$ polyvinylpyrrolidone using a mortar and pestle. The liquid was transferred to a $10-\mathrm{mL}$ centrifuge tube. The mortar was rinsed three times with $3 \mathrm{~mL}$ extract and transferred to a centrifuge tube. The liquid was mixed and extracted overnight, in darkness, at $4{ }^{\circ} \mathrm{C}$. The supernatant was collected after centrifugation at $12,000 g_{\mathrm{n}}\left(4^{\circ} \mathrm{C}\right)$ for $20 \mathrm{~min}$. The pellet was resuspended in the extract solution and extracted under the same conditions for $2 \mathrm{~h}$ more. The extract was centrifuged as before, the pellet was discarded, and the supernatants were combined. The extract was passed through a $\mathrm{C}_{18}$ Separon column (Agilent Technologies, Palo Alto, CA). The efflux was filtered through a $0.22-\mu \mathrm{m}$ membrane (Millipore) and dried with a stream of dinitrogen at $4{ }^{\circ} \mathrm{C}$. Following the instructions, all samples were used for the determination of IAA, ZR, GA, and ABA using enzymelinked immunosorbent assay kits (Shanghai Enzyme-linked Biotechnology, Shanghai, China). Each hormone was assayed in triplicate. The ratios of IAA, ZR, and GA to ABA were calculated, repeated three times.

Statistical analysis. All data were analyzed by $t$ tests using SPSS 18.0 (SPSS Inc., Chicago, IL), with significance set at $P \leq$ 0.05 . Pearson correlation analysis was also established using SPSS 18.0.

\section{Results}

Ploidy identification. There was no significant difference in DNA content between Korla fragrant pear and Zaomeixiang pear. They had the same ploidy and were all diploid (Fig. 1), which proves that the large-fruit characteristic of Zaomeixiang pear was not caused by chromosome doubling.

Fruit development and examination of cell size and number. The fruit growth and development period of Zaomeixiang pear were $\approx 15$ $\mathrm{d}$ less than that of Korla fragrant pear, but the former had a larger fruit size. The growth curves of fruit volume and weight of Korla fragrant pear and Zaomeixiang pear displayed an $\mathrm{S}$ shape, and fruit volume increased slowly during the early stage (Fig. 2). After 42 DAFB, the growth rate increased, and the difference in fruit size between the two varieties also became greater. After $56 \mathrm{DAFB}$, the fruit weight increased significantly. By $126 \mathrm{DAFB}$, the fruit of Zaomeixiang pear entered the mature stage, and the increased rate of fruit weight decreased. However, because of the long growth cycle of Korla fragrant pear, the fruit weight continued to increase; the rate of fruit weight increase decreased at 140 DAFB. The growth and weight dynamics of the two pears were similar.

Cell volume and cell number were calculated through observations and measurements based on paraffin sections of mesocarp cells during the fruit development stage (Figs. 3 and 4). Our results show that from full bloom to $42 \mathrm{DAFB}$, the cell volume was small, and the increase was slow. The cells were closely arranged and did not have intercellular spaces. There was no significant difference in cell volume between the two varieties before 28 DAFB, and it almost the same at 28 DAFBboth were about $10.9 \times 10^{-5} \mathrm{~mm}^{3}$. After 28 $\mathrm{d}$, the difference in cell volume became bigger and bigger. The results also showed that the number of cells increased continuously after pollination, and the difference was the greatest 28 DAFB, and was about $9.4 \times 10^{6}$. After 56 $\mathrm{DAFB}$, the cell number became stable; cell numbers of Korla fragrant pear and Zaomeixiang pear were $36 \times 10^{6}$ and $42 \times 10^{6}$, respectively. Therefore, the number of cells increased mainly during the early stage, and the volume of cells increased mainly during the late stage; both affected the fruit size.

Sugar contents during cell division. As the first sugar used in cell metabolism, glucose 

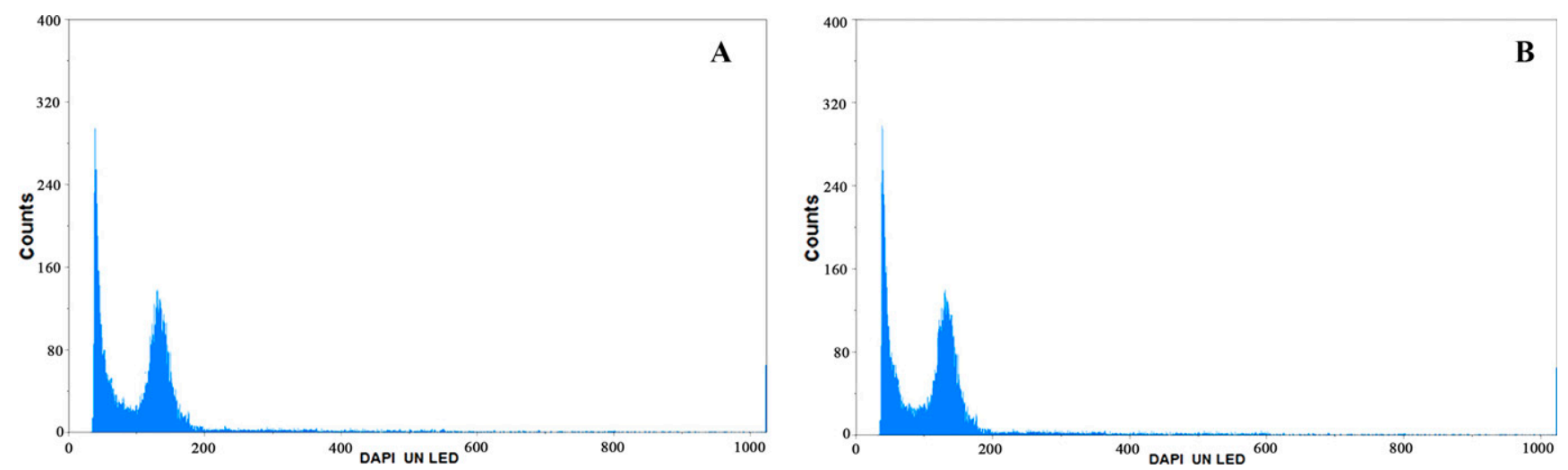

Fig. 1. Flow cytometry analysis of DNA of (A) Korla fragrant pear and (B) Zaomeixiang pear leaves.
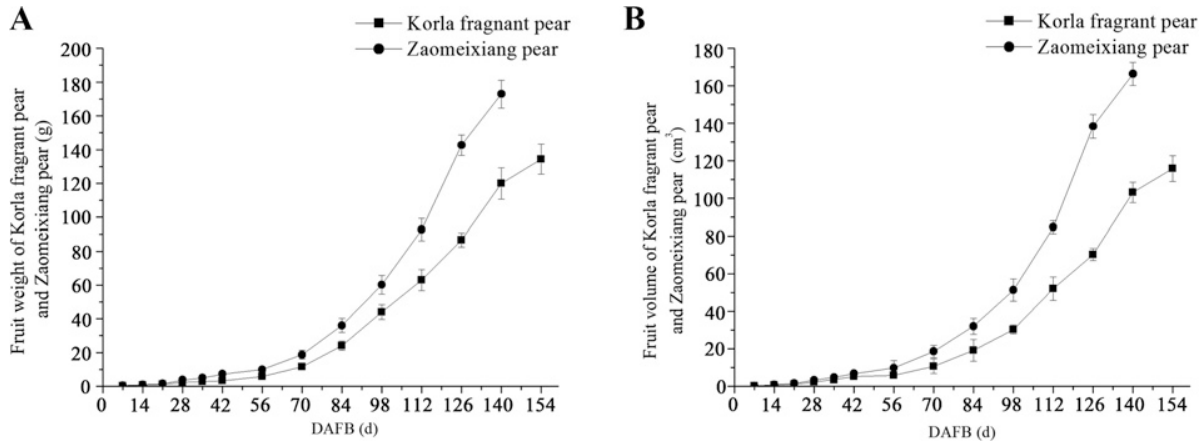

Fig. 2. Fruit size growth curves. Increments of (A) fruit weight and (B) fruit volume in Korla fragrant pear and Zaomeixiang pear were measured at different days after full bloom (DAFB).

levels vary widely during fruit development, exhibiting the pattern increase-decrease-increase during cell division (Fig. 5A). Before 14 DAFB, the contents of glucose in Korla fragrant pear and Zaomeixiang pear were similar, and the number of cells increased relatively slowly. Because of the rapid division of cells, glucose was consumed substantially and decreased rapidly during the young fruit stage of Zaomeixiang pear, and the cell number increased quickly at this time. The difference in glucose content at 21 DAFB was greatest at $4.80 \mathrm{ng} / \mathrm{g}$. The glucose content in Korla fragrant pear declined at 28 $\mathrm{DAFB}$, which indicated the fruit division of

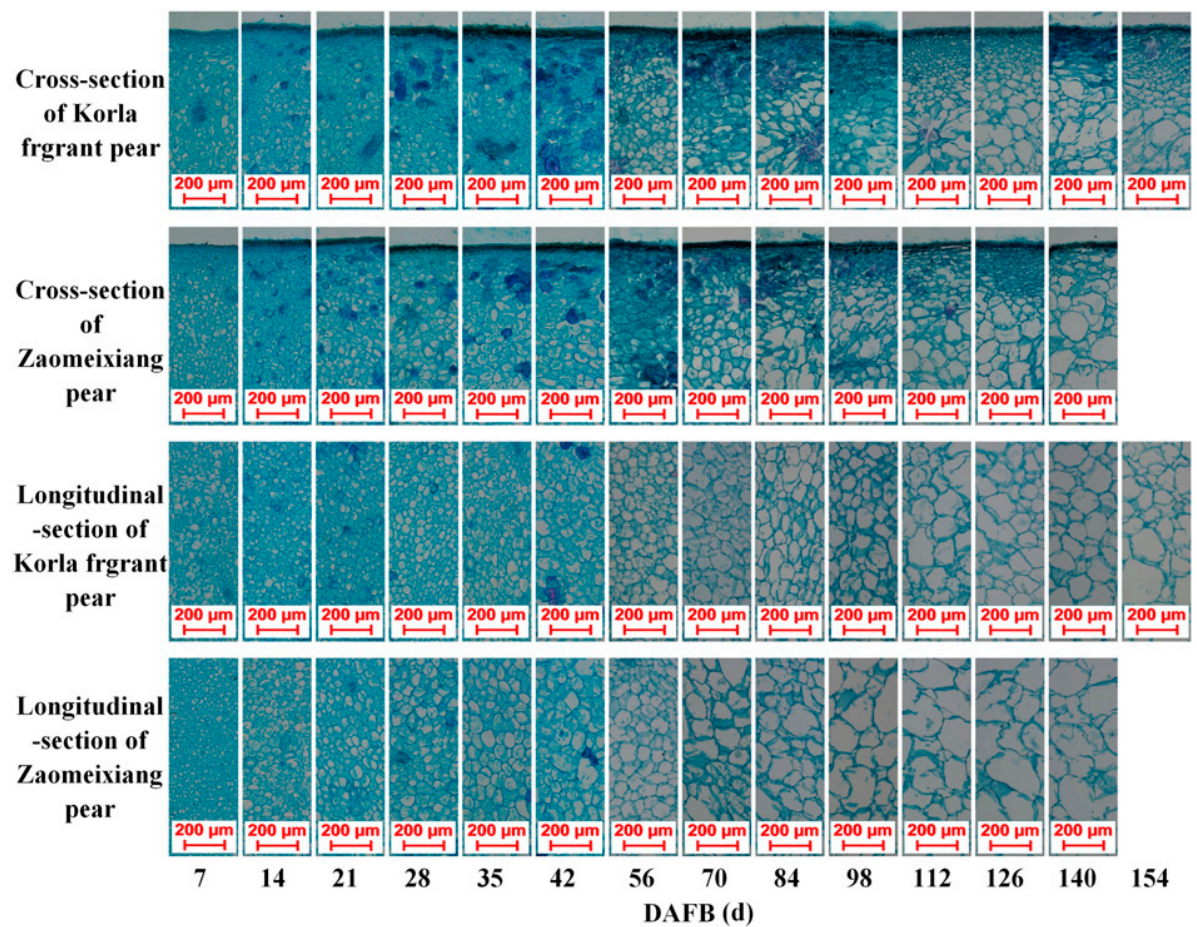

Fig. 3. Paraffin sections of mesocarp at different stages of Korla fragrant pear and Zaomeixiang pear. Bars represent $200 \mu \mathrm{m}$. DAFB, days after full bloom. 

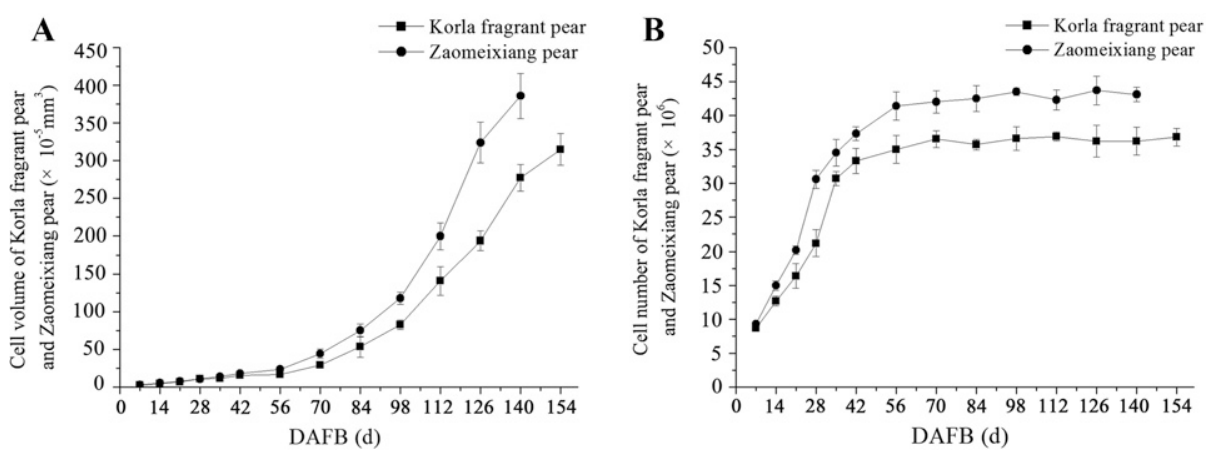

Fig. 4. Changes in (A) cell volume and (B) cell number at different stages of Korla fragrant pear and Zaomeixiang pear. DAFB, days after full bloom.

Zaomeixiang pear was more vigorous than that of Korla fragrant pear and consumed more glucose. Glucose increased rapidly after decreasing, showing that fruit increased the amount of glucose synthesis, thus ensuring sufficient anabolic substrate for cell division. There was a significant difference in glucose between the two varieties from 21 to 42 DAFB, and there were positive correlation coefficients between glucose and fruit weight, fruit volume, cell volume, and cell number of Zaomeixiang pear $(P \leq 0.05)$ (Table 1$)$. Therefore, glucose was one of the main sugar components that affected cell division during this period. There was no significant change in fructose between Korla fragrant pear and Zaomeixiang pear before $28 \mathrm{DAFB}$, indicating that the consumption of fructose in the process of fruit cell division was very low (Fig. 5B). After 28 DAFB, fructose increased in both types of pear. The changes in fructose were consistent. Although the difference in fructose between the two varieties was significant at each stage, it was only related positively to fruit volume and cell volume of Korla fragrant pear $(P \leq$ 0.05). The sucrose content of Korla fragrant pear and Zaomeixiang pear was less during cell division and did not exceed $1.1 \mathrm{mg} / \mathrm{g}$ fresh weight (Fig. 5C). Sucrose decreased first and then increased slightly, and the changes in sucrose in the two varieties were consistent. There was a significant difference in sucrose between the two varieties from 7 DAFB to 14 DAFB, but it did not correlate with fruit weight, fruit volume, cell volume, and cell number $(P \leq 0.05)$. The content of sorbitol in the two varieties was much greater than that of the other three kinds of sugars, and the changes were consistent and showed an obvious $\mathrm{S}$ curve (Fig. 5D). Sorbitol accumulated in a large amount during cell division. The sorbitol content of Zaomeixiang pear was greater than that of Korla fragrant pear. Except for at 7 DAFB, the difference in sorbitol between the two varieties was significant, and there were correlation coefficients between sorbitol and fruit weight, fruit volume, and cell volume of the two varieties $(P \leq 0.05)$.

Endogenous hormone contents during cell division. There was no significant difference in IAA content between Korla fragrant pear and Zaomeixiang pear during cell division, with the value ranged from 7.04 to $10.23 \mathrm{ng} /$ $\mathrm{g}$, so IAA may have little effect on the cell division rate and cell number difference (Fig. $6 \mathrm{~A})$. The content of IAA decreased during cell division and remained at a relatively low level. The result of correlation showed that IAA was negative related to fruit weight and cell volume of both varieties $(P \leq 0.05$,
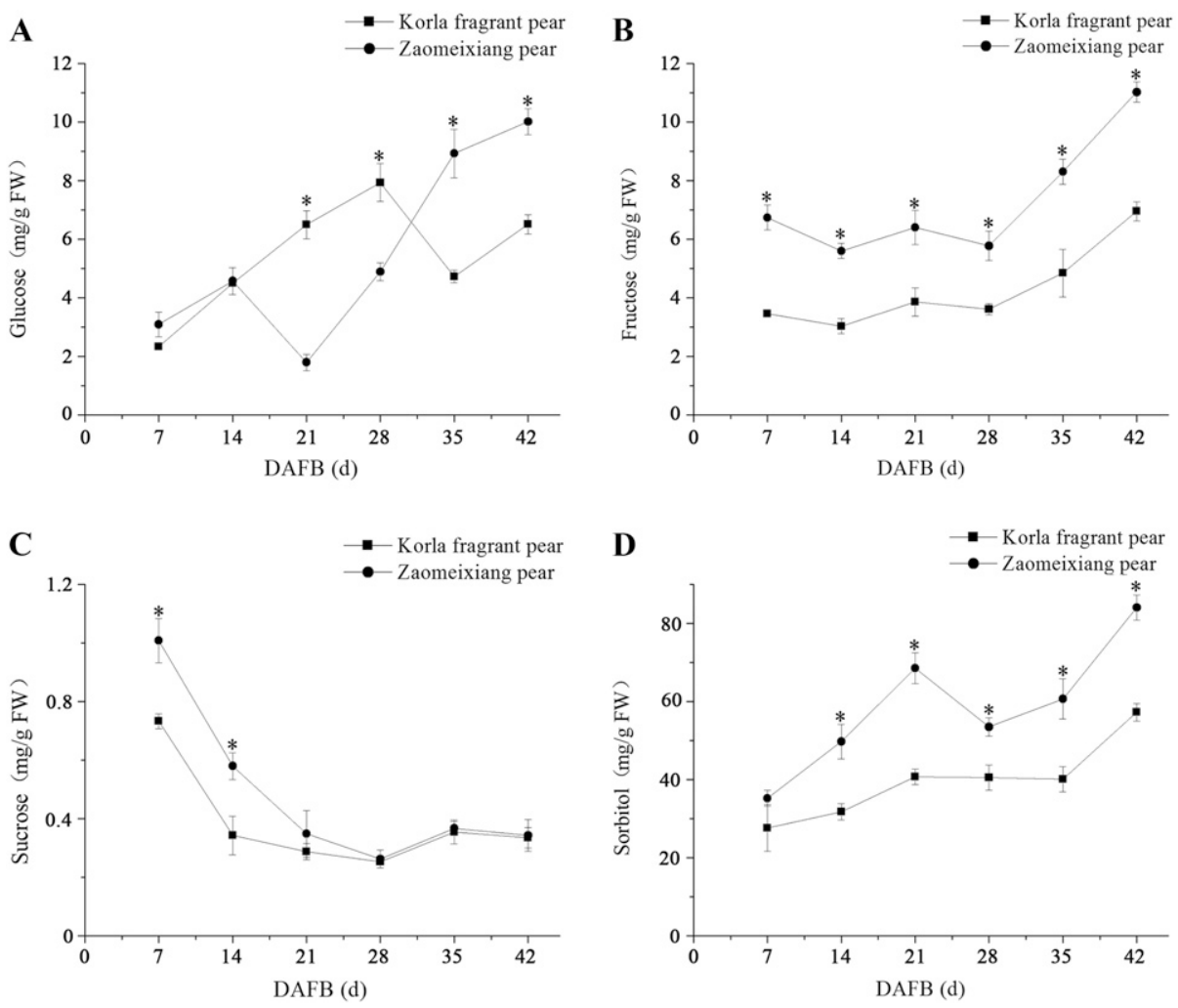

Fig. 5. Changes in (A) glucose, (B) fructose, (C) sucrose, and (D) sorbitol in the mesocarp during cell division of Korla fragrant pear and Zaomeixiang pear. FW, fresh weight. 
Table 1. Correlation analysis of sugar, fruit size, cell volume, and cell number.

\begin{tabular}{lcccc}
\hline Sugar (pear) & Fruit wt & Fruit volume & Cell volume & Cell no. \\
\hline Glucose (Korla fragrant pear) & 0.596 & 0.479 & 0.661 & 0.492 \\
Glucose (Zaomeixiang pear) & $0.903^{*}$ & $0.900^{*}$ & $0.866^{*}$ & $0.813^{*}$ \\
Fructose (Korla fragrant pear) & 0.804 & $0.929^{*}$ & $0.846^{*}$ & 0.857 \\
Fructose (Zaomeixiang pear) & $0.838^{*}$ & 0.841 & 0.807 & 0.660 \\
Sucrose (Korla fragrant pear) & -0.540 & -0.427 & -0.587 & -0.513 \\
Sucrose (Zaomeixiang pear) & -0.628 & -0.648 & -0.722 & -0.803 \\
Sorbitol (Korla fragrant pear) & $0.848^{*}$ & $0.911^{*}$ & $0.848^{*}$ & $0.856^{*}$ \\
Sorbitol (Zaomeixiang pear) & $0.898^{*}$ & $0.901^{*}$ & $0.924^{*}$ & $0.846^{*}$ \\
\hline
\end{tabular}

*Significant at $P \leq 0.05$.

Table 2). From 7 to $35 \mathrm{DAFB}$, the ZR content in the two varieties continued to decrease, then slightly increased during the last period of cell division (Fig. 6B). The ZR content of Zaomeixiang pear was always greater than that of Korla fragrant pear during the entire cell division stage, and the difference gradually increased during the rapid cell division period. Except for at 7 DAFB, the difference in $\mathrm{ZR}$ content between the two varieties was significant. It was related to fruit weight, fruit volume, cell volume, and cell number of Korla fragrant pear, and was also related to fruit volume and cell number of Zaomeixiang pear $(P \leq 0.05)$. There was a significant difference in GA between the two varieties at 7 , 35 , and 42 DAFB. The content of GA ranged from 5.39 to $9.13 \mathrm{ng} / \mathrm{g}$, and did not correlate with fruit weight, fruit volume, cell volume, and cell number $(P \leq 0.05)$, so GA may not affect directly the cell division rate and cell number of the two pear varieties (Fig. 6C). The content of GA in both varieties increased during the first stage, then decreased and reached the lowest level at 28 DAFB. There was no obvious regularity in the ABA content of the two varieties during cell division (Fig. 6D). Except at 7 DAFB, the ABA content of Korla fragrant pear was always greater than that of Zaomeixiang pear, and there was a significant difference in $\mathrm{ABA}$ content between the two varieties from 21 to 35 DAFB. The greatest difference was 30.87 $\mathrm{ng} / \mathrm{g}$, which appeared at 28 DAFB. In addition, ABA was also related negatively to fruit weight, fruit volume, cell volume, and cell number of Zaomeixiang pear $(P \leq 0.05)$.

The ratio of IAA, GA, and ZR to ABA showed a similar trend in the two varieties (Fig. 7). At $7 \mathrm{DAFB}$, the ratio of IAA/ABA and $\mathrm{ZR} /$ $\mathrm{ABA}$ in Korla fragrant pear was greater than that in Zaomeixiang pear. At other stages, the ratio of any hormone to ABA in Zaomeixiang pear was greater than that in Korla fragrant pear, especially at $28 \mathrm{DAFB}$, and the ratio of $\mathrm{ZR} / \mathrm{ABA}$ showed the biggest difference.

\section{Discussion}

Relationship between fruit size, cell size and number. Fruit growth is accomplished by cell division and cell expansion, which ultimately determine fruit size (Al-Hinai and Roper 2004; Harada et al., 2005). In large-fruit bud mutations formed by chromosome doubling, other tissues and organs may also increase in addition to fruit. This increase is usually caused by the size of the cells and has no obvious correlation with the number of cells (Yin et al., 1996). Changes resulting from fruit bud genetic mutations are only limited to the fruit; there are no significant differences in other tissues and organs (Wang et al., 2012). The results of a study of Cuiguan pear and its large-fruit bud mutation showed that the difference in fruit size was caused mainly by the difference in the number of cell divisions, and the difference in cell size was not significant (Shu et al., 2017). The results of a study of Nanguo pear and its large-fruit bud mutation showed that fruit size was affected by cell number and cell size (Zhang et al., 2011). Our results show that the fruit volume of Zaomeixiang pear was always greater than Korla fragrant pear after pollination. The cell volume of both varieties was the same at $28 \mathrm{DAFB}$, but the difference in cell number was the greatest. After 56 $\mathrm{DAFB}$, the cell number no longer increased, but the difference in cell volume became bigger and bigger. The increase in cell volume and cell number resulted in the difference in fruit size between the two varieties. It is similar to the results of the study of Nanguo pear (Zhang et al., 2011), and may be a result of the diversity of buds.

Effects of sugar contents on cell division. Glucose is a primary energy source for most cells and an important substrate for many biochemical reactions (Navale and Paranjape 2016). Glucose is a provider of carbon chains
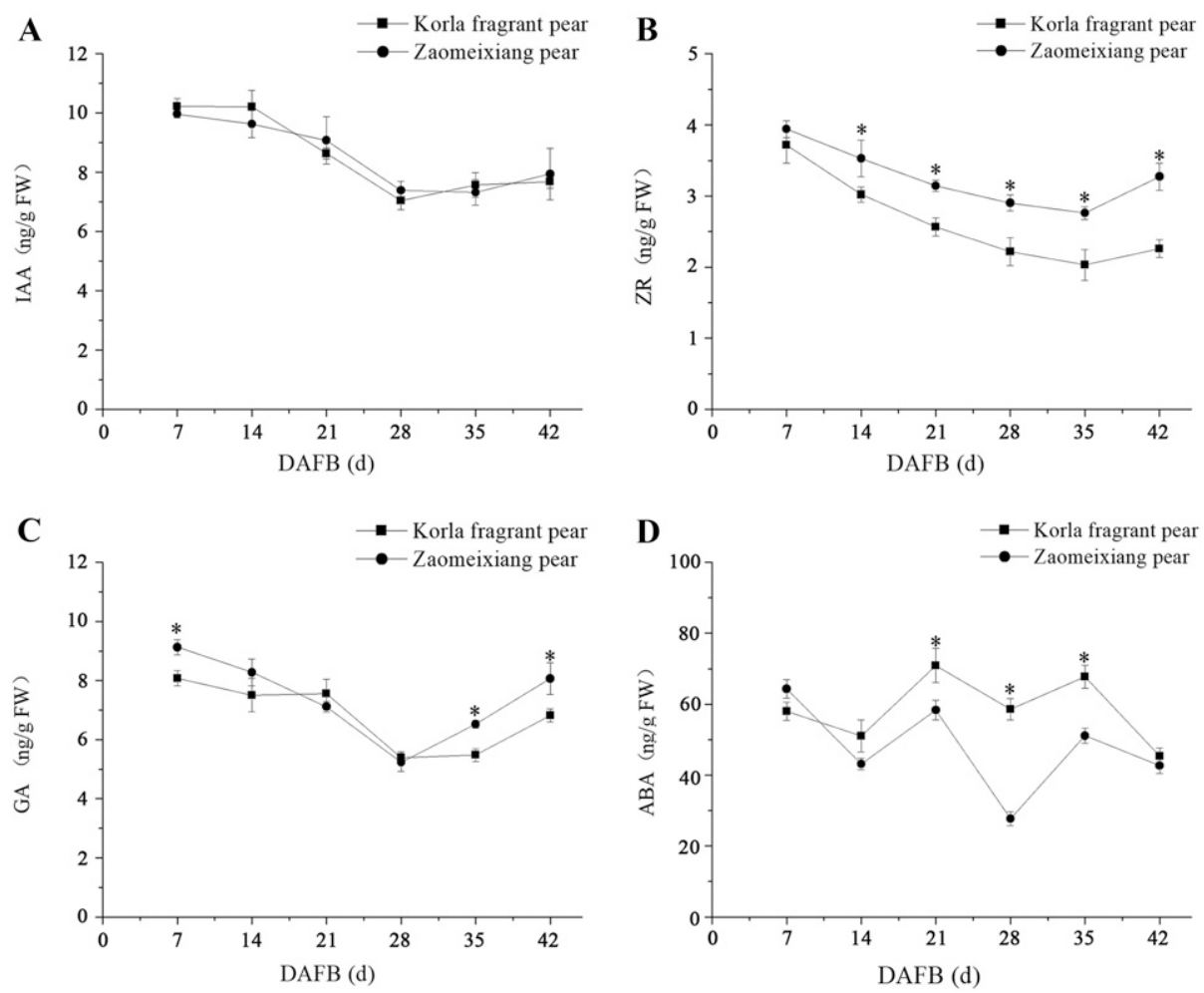

Fig. 6. Changes in (A) indoleacetic acid (IAA), (B), zeatin riboside (ZR), (C) gibberellic acid (GA), and (D) abscisic acid (ABA) in the mesocarp during cell division of Korla fragrant pear and Zaomeixiang pear. DAFB, days after full bloom; FW, fresh weight. 
Table 2. Correlation analysis of endogenous hormones, fruit size, cell volume, and cell number.

\begin{tabular}{llccc}
\hline Hormone (pear) & Fruit wt & Fruit volume & Cell volume & Cell no. \\
\hline ZR (Korla fragrant pear) & $-0.877^{*}$ & $-0.759^{*}$ & $-0.853^{*}$ & $-0.857^{*}$ \\
ZR (Zaomeixiang pear) & -0.574 & $-0.602^{*}$ & -0.656 & $-0.796^{*}$ \\
ABA (Korla fragrant pear) & -0.154 & -0.315 & -0.263 & -0.128 \\
ABA (Zaomeixiang pear) & $-0.457^{*}$ & $-0.425^{*}$ & $-0.450^{*}$ & $-0.553^{*}$ \\
GA (Korla fragrant pear) & -0.769 & -0.574 & -0.674 & -0.678 \\
GA (Zaomeixiang pear) & -0.336 & -0.344 & -0.395 & -0.592 \\
IAA (Korla fragrant pear) & $-0.895^{*}$ & -0.759 & $-0.860^{*}$ & -0.811 \\
IAA (Zaomeixiang pear) & $-0.812^{*}$ & -0.817 & $-0.828^{*}$ & -0.936 \\
\hline
\end{tabular}

$\mathrm{ZR}=$ zeatin riboside; $\mathrm{ABA}=$ abscisic acid; $\mathrm{GA}=$ gibberellic acid; $\mathrm{IAA}=$ indoleacetic acid.

* Significant at $P \leq 0.05$.

and energy during the synthesis of cellular constituents such as nucleic acids, amino acids, and phospholipids, and is consumed in large quantities during rapid cell division. The glucose consumption in Zaomeixiang pear was $\approx 14 \mathrm{~d}$ earlier than in Korla fragrant pear, indicating that Zaomeixiang pear was dividing more vigorously during this period. As a temporary storage form of carbohydrates, sucrose accumulates less during the early stage of pear fruit development, and it produces the glucose and fructose involved in metabolism. Sucrose decreased first and then increased slightly, which may have been a result of the large consumption of glucose during the early stage of cell division. Therefore, sucrose was decomposed to produce glucose to provide energy for cell division. During the late stage of cell division, sucrose is no longer needed to provide energy, and some of the remaining monosaccharides are composited temporarily to sucrose, so the sucrose content increases slightly. Sorbitol is the main form of transport for photosynthetic products in pear. Sorbitol cannot be used directly during the development of young fruit, but it is involved in the metabolism of fructose and glucose via sorbitol dehydrogenase and sorbitol oxidase. During the early stage of cell division, sorbitol accumulated in the fruit, and the amount of transformation was low. Greater amounts of sorbitol accumulated in Zaomeixiang pear than in Korla fragrant pear, which may be the reason that the content of glucose and fructose in young fruit of Zaomeixiang pear was greater than that in Korla fragrant pear. During the rapid cell division phase, glucose is consumed in large quantities whereas fructose is barely consumed, so sorbitol is widely used to synthesize glucose for metabolism. By comparing the changes in sorbitol content during the rapid cell division stage of the two varieties, we determined the sorbitol content of Zaomeixiang pear to be much greater than that of Korla fragrant pear. These results are consistent with the results of cell division between Nanguo pear and its large-fruit bud mutation (Zhang et al., 2011). Fructose increased during the later cell division stage in both Korla fragrant pear and Zaomeixiang pear, which may be because they are both fructoseaccumulating fruit.

Effects of endogenous hormones on cell division. Cytokinins play an important role in cell division (Kieber and Schaller, 2018). ZR decreased first and then increased during cell division in Korla fragrant pear and Zaomeixiang pear. This may be because the fruit, leaves, and new tips grew synchronously fast during early fruit development, the cytokinin produced by the root tip is supplied preferentially to the leaves and new growth, and fruit must use fruit-produced cytokinin for cell division. After 35 DAFB, the leaves mature and fewer cytokinins are required. The cytokinin produced by the root tips was supplied to the fruit, and ZR content increased. ZR content of Zaomeixiang pear was always greater than that of Korla fragrant pear during whole-cell division. This is consistent with the results of studies of fruit size in orange and pear (Liu et al., 2020; Pang et al., 2017). ZR can promote the input and accumulation of photoassimilates, which may cause Zaomeixiang pear to have a greater sorbitol content than Korla fragrant pear. IAA is involved in promoting cell wall formation and cell growth, and a low concentration of IAA helps cytokinins promote cell division. Research in lychee showed that IAA was not related to fruit size but was related to fruit set ( $\mathrm{Li}$ et al., 2004). However, the IAA content of Nanguo pear during the early stage of fruit development is less than that in its large-fruit bud mutation (Zhang et al., 2011). In our study, there was almost the same content of IAA during cell division, which may be related to
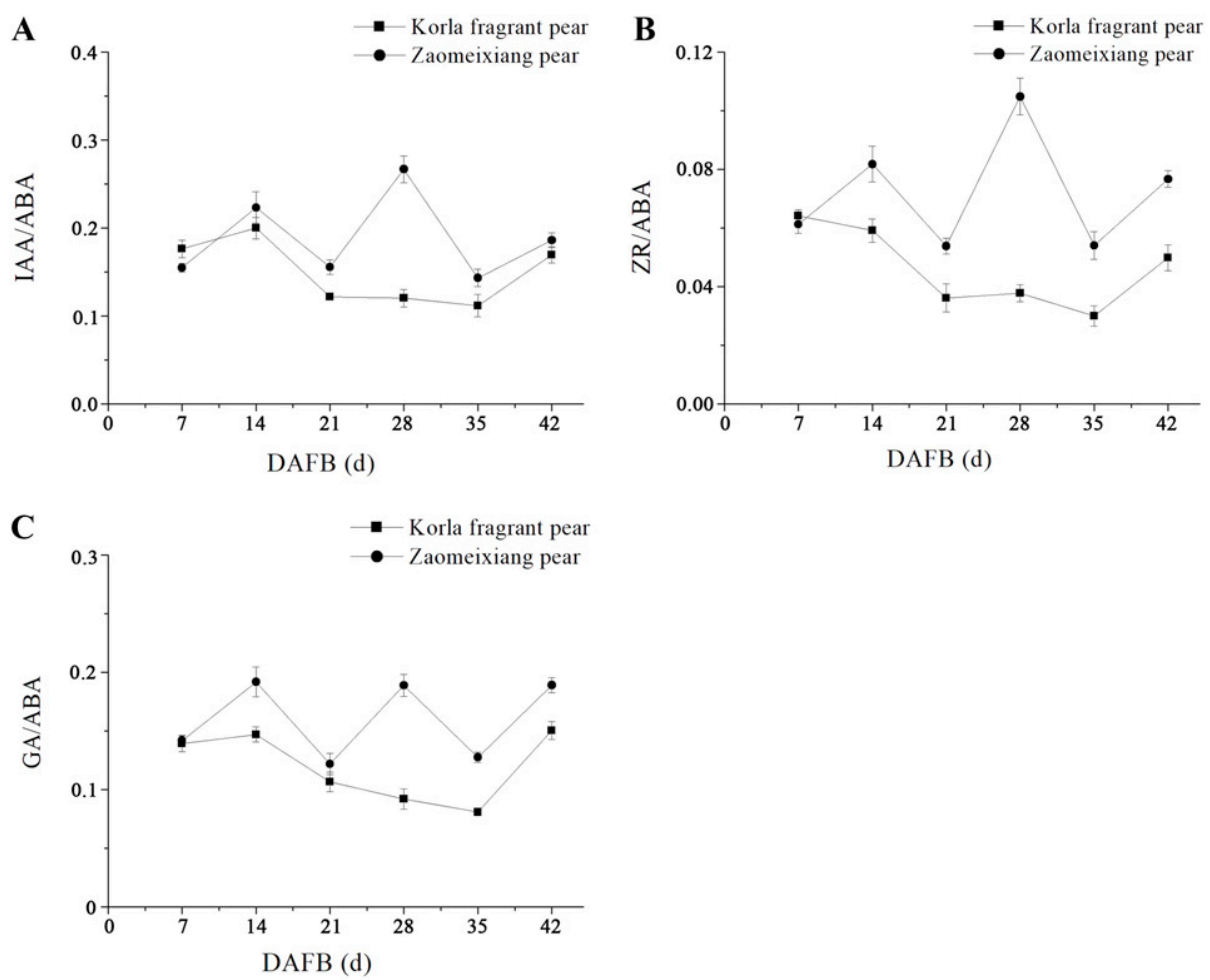

Fig. 7. Changes in the ratio of (A) indoleacetic acid (IAA)/abscisic acid (ABA), (B) zeatin riboside (ZR)/ABA, and (C) gibberellic acid (GA)/ABA in the mesocarp during cell division of Korla fragrant pear and Zaomeixiang pear. DAFB, days after full bloom. 
the difference between different species and varieties. GA trends in both varieties showed a decrease first and then an increase. This may be because gibberellin mainly promotes cell elongation and antagonizes cytokinin (Shahnejat-Bushehri et al., 2016), so gibberellin in young fruit is decreased before cell division. During the late stage of cell division, GA increases gradually and cell volume begins to increase further, leading to an increase in fruit size. Studies in Nai plum, pear, and lychee showed that the formation of small fruit was mainly the result of the limitation of cell division, and the decrease in cell number was closely related to the increase in ABA content in fruit ( $\mathrm{Li}$ et al., 2004; Liao et al., 2018; Shu et al., 2017). In our experiment, except at 7 DAFB, the ABA content of Korla fragrant pear was always greater than that of Zaomeixiang pear.

In addition to the content of endogenous hormones, the ratio of different hormones also affected fruit cell division. In research of avocado, the reduced IAA/ABA ratio in mesocarp tissue may be part of the syndrome associated with the appearance of a small-fruit phenotype (Nicky and Keith 2001). In Nai plum, the lower ratio of $\mathrm{IAA} / \mathrm{ABA}, \mathrm{ZR} / \mathrm{ABA}$, and $\mathrm{GA} / \mathrm{ABA}$ correlated negatively with fruit size (Liao et al., 2018). Our experiment included the study of three hormone (IAA, ZR, and GA)-to-ABA ratios. We found that, at $7 \mathrm{DAFB}$, when the ratio of IAA/ABA, ZR/ABA, and GA/ABA in the two varieties was similar, the difference in cell number was not significant. During other periods, the ratios of IAA/ABA, ZR/ABA, and $\mathrm{GA} / \mathrm{ABA}$ in Zaomeixiang pear were greater than those in Korla fragrant pear, and the difference in cell number was also increased. Interestingly, at $28 \mathrm{DAFB}$, the difference in cell number was the greatest. This may indicate that the ratio of endogenous hormone contents was the main reason for the difference in cell number.

\section{Conclusion}

The difference in fruit size between Korla fragrant pear and its bud mutation Zaomeixiang pear was not caused by chromosome doubling, but was determined by cell volume and cell number, and 28 DAFB was the most different period of cell growth. The different contents of glucose, sorbitol, ZR, and ABA might be related to cell division in Korla fragrant pear and Zaomeixiang pear. The ratio of endogenous hormone contents was the main reason for the difference in cell number, which affected the fruit size of Korla fragrant pear and Zaomeixiang pear. According to the results of our study, we suggest spraying appropriate cytokinin after pollination to increase the hormone ratio and promote cell division, which is of great importance to the large-fruit high-quality cultivation of Korla fragrant pear.

\section{Literature Cited}

Al-Hinai, Y.K. and T.R. Roper. 2004. Rootstock effects on growth, cell number, and cell size of
'Gala'. Apples. J. Amer. Soc. Hort. Sci. 129(1):37-41, doi: 10.21273/JASHS.129.1.0037.

Breuninger, H. and M. Lenhard. 2010. Control of tissue and organ growth in plants. Curr. Top. Dev. Biol. 91:185-220, doi: 10.1016/S00702153(10)91007-7.

Cerri, M., A. Rosati, F. Famiani, and L. Reale. 2019. Fruit size in different plum species (genus Prunus L.) is determined by post-bloom developmental processes and not by ovary characteristics at anthesis. Scientia Hort. 255:1-7, doi: 10.1016/j.scienta.2019.04.064.

Dahan, Y., R. Rosenfeld, V. Zadiranov, and V. Irihimovitch. 2010. A proposed conserved role for an avocado fw2.2-like gene as a negative regulator of fruit cell division. Planta 232(3):663676, doi: 10.1007/s00425-010-1200-3.

Filipe, S., A. Eduardo, P. Rafael, C. Elisa, R. Gregory, I.F. Ana, and P. Róberson. 2019. Influence of temperature on the development of peach fruit in a subtropical climate region. Agronomy 9(1):20, doi: 10.3390/Agronomy.9010020.

Gonzalez, N., H. Vanhaeren, and D. Inzé. 2012. Leaf size control: Complex coordination of cell division and expansion. Trends Plant Sci. 17(6):332-340, doi: 10.1016/j.tplants.2012.02.003.

Harada, T., W. Kurahashi, M. Yanai, Y. Wakasa, and T. Satoh. 2005. Involvement of cell proliferation and cell enlargement in increasing the fruit size of Malus species. Scientia Hort. 105(4):447-456, doi: 10.1016/j.scienta.2005.02.006.

Hu, M., Z.H. Qiu, P. Zhou, L.F. Xu, and J.K. Zhang. 2012. Proteomic analysis of 'Zaosu' pear (Pyrus bretschneideri Rehd.) and its red skin bud mutation. Proteome Sci. 10(1):51, doi: 10.1186/1477-5956-10-51.

Kanayama, Y. 2017. Sugar metabolism and fruit development in the tomato. Hort. J. 86(4):417425, doi: 10.2503/hortj.OKD-IR01.

Kano, Y. 2003. Effects of GA and CPPU treatments on cell size and types of sugars accumulated in Japanese pear fruit. J. Hort. Sci. Biotechnol. 78(3):331-334, doi: 10.1080/14620316.2003.115 11627.

Kieber, J.J. and G.E. Schaller. 2018. Cytokinin signaling in plant development. Development 145(4):dev149344, doi: 10.1242/dev.149344.

Li, J.G., B.Y. Zhou, X.M. Huang, and H.B. Huang. 2004. Studies on endogenous hormones in the pericarp of 'Feizixiao' litchi in relation to different fruit sizes from early and late bloom. Acta Hort. Sin. 31(1):73-75, doi: 10.1016/S01660934(98)00031-7.

Li, X.W., H. Zhang, J. Han, and K.N. Teng. 2007. Changes in postharvest physiology and quality of fragrant pear fruit with different maturities at harvest. Xinjiang Agr. 44(3):264-267.

Liao, R., X. Wu, Z. Zeng, L. Yin, and Z. Gao. 2018. Transcriptomes of fruit cavity revealed by de novo sequence analysis in Nai plum (Prunus salicina). J. Plant Growth Regulat. 37(3):730-744, doi: 10.1007/s00344-017-9768-5.

Lim, S.D., W.C. Yim, D. Liu, R. Hu, X. Yang, and J.C. Cushman. 2018. A Vitis vinifera basic helix-loop-helix transcription factor enhances plant cell size, vegetative biomass and reproductive yield. Plant Biotechnol. J. 16(9):1595-1615, doi: 10.1111/pbi.12898.

Liu, X.Y., L. Li, and Y.P. Cai. 2006. Effect of light intensity for formation of stone cell and correlation between activity of endogenous IAA, ZR and $\mathrm{ABA}$ and formation of stone cell in $\mathrm{Pyr}$ us.spp. Acta Laser Biol. Sinica 15(2):161-166, doi: 10.3969/j.issn.1007-7146.2006.02.011.

Liu, X.Y., J. Li, M. Huang, and J.Z. Chen. 2015. Mechanisms for the influence of citrus rootstocks on fruit size. J. Agr. Food Chem. 63(10):2618-2627, doi: 10.1021/jf505843n.
Liu, X., Y. Pan, C. Liu, Y. Ding, and H. Meng. 2020. Cucumber fruit size and shape variations explored from the aspects of morphology, histology, and endogenous hormones. Plants 9(6):772, doi: 10.3390/plants9060772.

Maricarmen, B., M. Liliam, A. Anibal, V. Monika, M. Juan-Pablo, T. Dante, D. Bruno, G.A. Mauricio, and F. Lida. 2019. Expression of two indole3-acetic acid (IAA)-amido synthetase (GH3) genes during fruit development of raspberry $(R u-$ bus idaeus Heritage). Scientia Hort. 246:168-175, doi: 10.1016/j.scienta.2018.09.077.

Nagashima, Y., M. Sudo, M. Yahata, A. Tominaga, and H. Mukai. 2019. Varietal differences in flesh cell number and size of japanese plum fruit. Hort. Res. Japan 18(1):39-44, doi: 10.2503/ hrj.18.39.

Navale, A.M. and A.N. Paranjape. 2016. Glucose transporters: Physiological and pathological roles. Biophys. Rev. 8(1):5-9, doi: 10.007/ s12551-015-0186-2.

Nicky, T. and C. Keith. 2001. Plant hormone homeostasis and the control of avocado fruit size. Plant Growth Regulat. 35:247-255, doi: 10.1007/s00344-017-9768-5.

Pang, S.P., C.C. Dong, Y.T. Ma, C. Qian, S.L. He, R.J. Xie, and L. Deng. 2017. The roles of two CsAREB transcription factors in the development of citrus fruit. Acta. Hort. Sin. 44(3):441-451, doi: 10.16420/j.issn.0513-353x.2016-0580.

Shahnejat-Bushehri, S., D. Tarkowska, Y. Sakuraba, and S. Balazadeh. 2016. Arabidopsis NAC transcription factor JUB1 regulates GA/BR metabolism and signalling. Nat. Plants 2(3):1-9, doi: 10.1038/nplants.2016.13.

Shu, S.S., X. Li, J. Luo, S.L. Bai, and Y.Y. Teng. 2017. Studies on cytology and related gene expression pattern of a large-fruited bud mutant from 'Cuiguan' pear (Pyrus pyrifolia). J. Fruit Sci. 34(6):660-669, doi: 10.13925/j.cnki.gsxb. 20160129.

Simona, N., C. Janine, L.B. Helen, G.H. Katrin, T. Tania, J. Dan, H.T. Amali, and C.R. Annette. 2020. Phytohormone and transcriptomic analysis reveals endogenous cytokinins affect kiwifruit growth under restricted carbon supply. Metabolites 10(1):23, doi: 10.3390/metabo10010023.

Tian, J., B. Zeng, S.P. Luo, X.G. Li, B. Wu, and J. Li. 2016. Cloning, localization and expression analysis of two fw2.2-like genes in small-and largefruited pear species. J. Integr. Agr. 15(2):282-294, doi: 10.1016/S2095-3119(15)61075-9.

Wang, Y.Z., M.S. Dai, S.J. Zhang, and Z.B. Shi. 2012. A review on pear bud sport breeding and research progress in mutant mechanisms. J. Fruit Sci. 29(4):676-682, doi: 10.13925/j.cnki. gsxb.2012.04.029.

$\mathrm{Wu}, \mathrm{T}$. 2011. The characteristics of sugar accumulation and its relationship with fruit size during the fruit development in 'Hosut' and 'Yali' pear. Nanjing Agricultural University, $\mathrm{PhD}$ Diss.

Yin, Y.S., Z.K. Xu, A.B. Zhang, S.Z. Yang, and Q.S. Wang. 1996. Breeding of a tetraploid variety of bud mutation of Bartlett pear. Chin. Agr. Sci. Bull. 12(5):22-23.

Zaky, A.S., N. Pensupa, Á. Andrade-Eiroa, G.A. Tucker, and C. Du. 2017. A new HPLC method for simultaneously measuring chloride, sugars, organic acids and alcohols in food samples. J. Food Compos. Anal. 56:25-33, doi: 10.1016/j.jfca.2016.12.010.

Zhang, C.Z. and X.T. Ma. 1995. Comparison of several common methods to measure the volume of fruit. China Fruits 2:44-45.

Zhang, C., K. Tanabe, S. Wang, F. Tamura, A. Yoshida, and K. Matsumoto. 2006. The impact of cell division and cell enlargement on the evolution of fruit size in Pyrus pyrifolia. Ann. 
Bot. 98:537-543, doi: 10.1016/S0960-1481(98) 00517-5.

Zhang, S.J., J. Wu, H. Chen, C. Gu, S.T. Tao, J.Y. Wu, and S.L. Zhang. 2011. Identification of differentially expressed genes in a spontaneous mutant of 'Nanguoli' pear (Pyrus ussuriensis Maxim) with large fruit. J. Hort. Sci. Biotechnol.
86(6):595-602, doi: 10.1080/14620316.2011. 11512809 .

Zhang, X.Y., Z.X. Li, B.Y. Yin, Z.Y. Li, Y. Zhang, J.Z. Xu, Q.W. Li, and J.Z. Shao. 2019. Transcriptome analysis of large-fruit mutant during the early development of fruit in 'Tonami' apple (Malus domestica). J. Agr.
Biotechnol. 27(12):2140-2149, doi: 10.3969/ j.issn.1674-7968.2019.12.006.

Zhao, J.R., F. Shen, Y. Gao, D.J. Wang, and K. Wang. 2019. Parallel bud mutation sequencing reveals that fruit sugar and acid metabolism potentially influence stress in Malus. Intl. J. Mol. Sci. 20(23):5988, doi: 10.3390/ijms20235988. 